\title{
Multi-spindle drilling of Al2024 alloy and the effect of TiAIN and TiSiN coated carbide drills for productivity improvement
}

\section{Muhammad Aamir ( $\square$ m.aamir@ecu.edu.au )}

School of Engineering, Edith Cowan University, Joondalup, WA 6027, Australia

\section{Majid Tolouei-Rad}

School of Engineering, Edith Cowan University, Joondalup, WA 6027, Australia

\section{Khaled Giasin}

University of Portsmouth, School of Mechanical and Design Engineering, Portsmouth P01 3DJ, UK

\section{Research Article}

Keywords: Multi-spindle drilling, TiAIN, TiSiN, Thrust force, Surface roughness, Hole quality

Posted Date: March 16th, 2021

DOl: https://doi.org/10.21203/rs.3.rs-324854/v1

License: (1) (i) This work is licensed under a Creative Commons Attribution 4.0 International License.

Read Full License

Version of Record: A version of this preprint was published at The International Journal of Advanced Manufacturing Technology on April 20th, 2021. See the published version at https://doi.org/10.1007/s00170-021-07082-7. 
Multi-spindle drilling of Al2024 alloy and the effect of TiAIN and TiSiN coated carbide drills for productivity improvement

Muhammad Aamir ${ }^{1 *}$, Majid Tolouei-Rad ${ }^{1}$, and Khaled Giasin ${ }^{2 *}$

${ }^{1}$ School of Engineering, Edith Cowan University, Joondalup, WA 6027, Australia

${ }^{2}$ School of Mechanical and Design Engineering, University of Portsmouth, Portsmouth PO1 3DJ, UK

\section{Contact information:}

Corresponding author (1):

${ }^{1 *}$ Muhammad Aamir

m.aamir@ecu.edu.au

School of Engineering, Edith Cowan University, Joondalup, WA 6027, Australia

\section{${ }^{1}$ Majid Tolouei-Rad}

m.rad@ecu.edu.au

School of Engineering, Edith Cowan University, Joondalup, WA 6027, Australia

Corresponding author (2):

${ }^{2 * K h a l e d ~ G i a s i n}$

khaled.giasin@port.ac.uk

University of Portsmouth, School of Mechanical and Design Engineering, Portsmouth PO1 3DJ, UK

\section{Acknowledgements}

The authors would like to thank Edith Cowan University, Australia, for the awarded (ECU-HDR) higher degree research scholarship and for providing support on this research. 


\section{Multi-spindle drilling of Al2024 alloy and the effect of TiAIN and TiSiN coated carbide drills for productivity improvement}

\section{Abstract}

High precision drilling is required to ensure the structural integrity of the aircraft. Therefore, strict quality controls are required to ensure optimum hole quality since hundreds of thousands of holes are drilled into different aircraft structures. The large number of holes required for riveting means that their installation must be carried out in a fast and precise manner. This can be achieved using multi-head drilling tools that can drill several holes simultaneously. The current study investigated the use of a multi-spindle drill head that can produce three holes simultaneously. Uncoated carbide and TiAIN- and TiSiN- coated carbide drills were used to assess cutting forces, hole surface roughness, burr formations and tool condition when machining Al2024 aerospace alloy under dry machining conditions. Analysis of variance was employed for estimating the relationships between the input parameters (spindle speed, feed and tool coating) and the studied hole quality metrics. Further, a regression model was developed with a regression coefficient $\left(R^{2}\right)$ of more than $90 \%$ for the prediction of measured responses. Interestingly, better results in lower thrust force and surface roughness were obtained using the uncoated carbide drills compared with TiAIN and TiSiN. While the performance of TiAIN was found to be better than those obtained from TiSiN.

Keywords: Multi-spindle drilling; TiAIN; TiSiN; Thrust force; Surface roughness; Hole quality.

\section{Introduction}

Riveting which is achieved by hole drilling, is the most common method used for the assembly of aircraft structures. The number of holes in an aircraft structure can vary from several thousand to multi-million [1]. Boeing 747, introduced in 1969, contained six million parts, of which half are fasteners [2]. The quality of holes is essential to ensure assembled structures in the aircraft to maintain high structural integrity during the life service of the aircraft. Hole quality metrics such as the surface roughness, burr formations and geometrical tolerances such as hole size and circularity are of great importance. For example, the inside of the hole must be free of defects such as burrs that could promote structural weaknesses under the stress of flight. Moreover, hole size, which is out of the recommended tolerance range, can increase the vibrations in the aircraft structure and promote increased levels of high cycle fatigue and crack propagation [3]. Moreover, the contact between the cutting tool and the chip during the drilling process can promote thermal and mechanical stresses, which can increase the surface roughness in the hole. This, in return, would create undesirable regions of stress concentration from which cracks can initiate [4]. The fuselage skins of modern aircraft are usually made of aluminium and titanium alloys [5]. Machining holes in 
those alloys is generally carried out without coolants, which increases heat and oxidation on the tool and workpiece. Moreover, it can promote faster tool wear and lowers the overall hole quality. Therefore, cutting tools are coated with thin films of chemical compounds that can substantially enhance the properties and performance of a cutting tool.

The advancement in cutting tools is one of the most important aspects of any cutting operation due to high economic demands in the manufacturing industry. A cutting tool must be stronger and efficient to machine materials at the highest possible productivity [6]. High productivity is achieved at a high cutting speed that associates a large amount of heat which might increase the power consumption, and subsequently, the cutting force increases [7]. In this regard, coatings on the tools have been introduced to increase the life of the tool, thus reducing the manufacturing cost due to less frequent tool changes [8].

Chemical vapour deposition (CVD) and physical vapour deposition (PVD) hard coatings are two techniques employed for cutting tools for improving tool life and machining performance. In the CVD technique, thin films are deposited on the cutting tools through various chemical reactions, whereas the PVD technique includes the deposition of the thin film on the tools through a physical technique such as sputtering and evaporation [7]. Coatings are deposited on the substrate either as a single layer or multi-layer depending on the requirement of applications [9].

In the manufacturing industry, drilling is the most commonly used material removal process, in which the goal is to improve the surface finish and dimensional accuracy to increase productivity [10]. However, it is difficult to achieve all these parameters when it comes to machining aluminium alloys. Therefore, there is a high possibility of tool wear in the machining of aluminium, especially in a dry cutting environment [11]. Hence, the selection of an appropriate cutting tool is required, which is crucial for the improvement of productivity in any manufacturing industry [7].

Haja Syeddu Masooth and Jayakumar [12] worked on dry machining of AA5052 to assess the surface roughness and cylindricity of the holes. The drill bits used were uncoated HSS (High-Speed Steel) and TiN, AICrN, TiAIN HSS coated drills. It was found in their study that the TiAIN performed better by giving lower values of surface roughness, less cylindricity error and less tool wear. Kuram [13] evaluated the surface roughness, top burr width, and tool wear using monolayer and two-layer coated inserts in milling of Al2124 aluminium alloy. It was concluded that coated inserts with two layers (TiCN + TiN and AITiN + TiN) and monolayer TiCN coated inserts gave better machining performance with respect to AITiN and TiAIN coated inserts. In another study by Wang et al. [14], the life of TiSiN tools was found longer than TiAIN when high-speed machining experiments were performed to analyse the wear and breakage of the tools. Dumkum et al. [15] reported that the TiAIN gave the lowest surface roughness and smallest tool wear while TiN-coated drills resulted in the 
lowest thrust force and torque. Kurt et al. [16] recommended using HSS-Co 5\%, during dry drilling of Al2024 for minimal hole diameter deviations compared with an uncoated, TiN and TiAIN coated drills.

The above studies indicate that most previous studies with different tool materials and coatings are based on the one-shot drilling process or other machining processes. Further, the use of the coatings on wear mechanism needs further understanding where the relationship between coating's characterization and machining performance needs further assessment. Also, the coatings on the tools used in the machining of aluminium are still contradictory and need further research. Therefore, this study investigates the effect of cutting tool coatings (TiAIN- and- TiSiN) on the machinability of Al2024 using the multi-hole simultaneous drilling approach, which has received less attention from researchers. Multispindle drilling is useful for manufacturing industries where machining time and high productivity are essential for the machining process [17-20]. The coatings were selected based on their excellent hardness and high thermal and oxidation resistance [21]. Therefore, the selection of suitable tool material together with the use of multi-hole drilling would further enhance productivity in any manufacturing industry.

\section{Materials and methods}

In this study, drilling experiments were conducted using a vertical turret manual milling machine in a dry environment using an adjustable SUNHER type MH30/13 multi-spindle drill head. The spindle speeds selected were 1007, 2015, and $3025 \mathrm{rpm}$, while the feed rates were $0.04,0.08$, and $0.14 \mathrm{~mm} / \mathrm{rev}$, similar to the previous studies [6]. Furthermore, aggressive drilling results in high vibration and cutting temperature that could affect the hole quality [22]. A set of three drill bits each for uncoated carbide, TiAIN, and TiSiN were tested using the multi-spindle simultaneous drilling process. First, drilling was carried out using uncoated carbide drills, and then the same procedure was carried out for TiAIN and TiSiN. The workpiece material was Al2024 aluminium alloy which is used in the fuselage skins of aircraft [23]. The cutting tools were $6 \mathrm{~mm}$ uncoated, TiAIN- and TiSiN-coated carbide twist drills. Some of the properties of cutting tools used in this study are given in Table 1. The point angle and helix angle of the drill bits were $140^{\circ}$ and $30^{\circ}$, respectively. The thickness of the workpiece was $10 \mathrm{~mm}$.

Table 1 Properties of cutting tools $[21,24,25]$

\begin{tabular}{llll}
\hline Coatings & Oxidation temp $\left({ }^{\circ} \mathrm{C}\right)$ & Hardness $(\mathrm{GPa})$ & Friction coefficient \\
\hline TiAIN & $700-800$ & 32 & $0.5-0.7$ \\
\hline TiSiN & 1000 & 35 & 0.6 \\
\hline Uncoated & 500 & 26 & $0.4-0.6$ \\
\hline
\end{tabular}

A KISTLER 9257A dynamometer was used to measure the thrust force $\left(F_{z}\right)$ [26]. The average surface roughness $\left(R_{a}\right)$ was measured using the surface roughness tester, and the 
burrs were observed using the digital microscope, similar to a previous study [27]. The tool conditions were examined with the use of an optical microscope. Analysis of variance (ANOVA) and regression analysis was also performed to find the percentage contribution of the input parameters and develop a model for predicting the output parameters. The details of the machines/equipment used in the study are given in Figure 1.

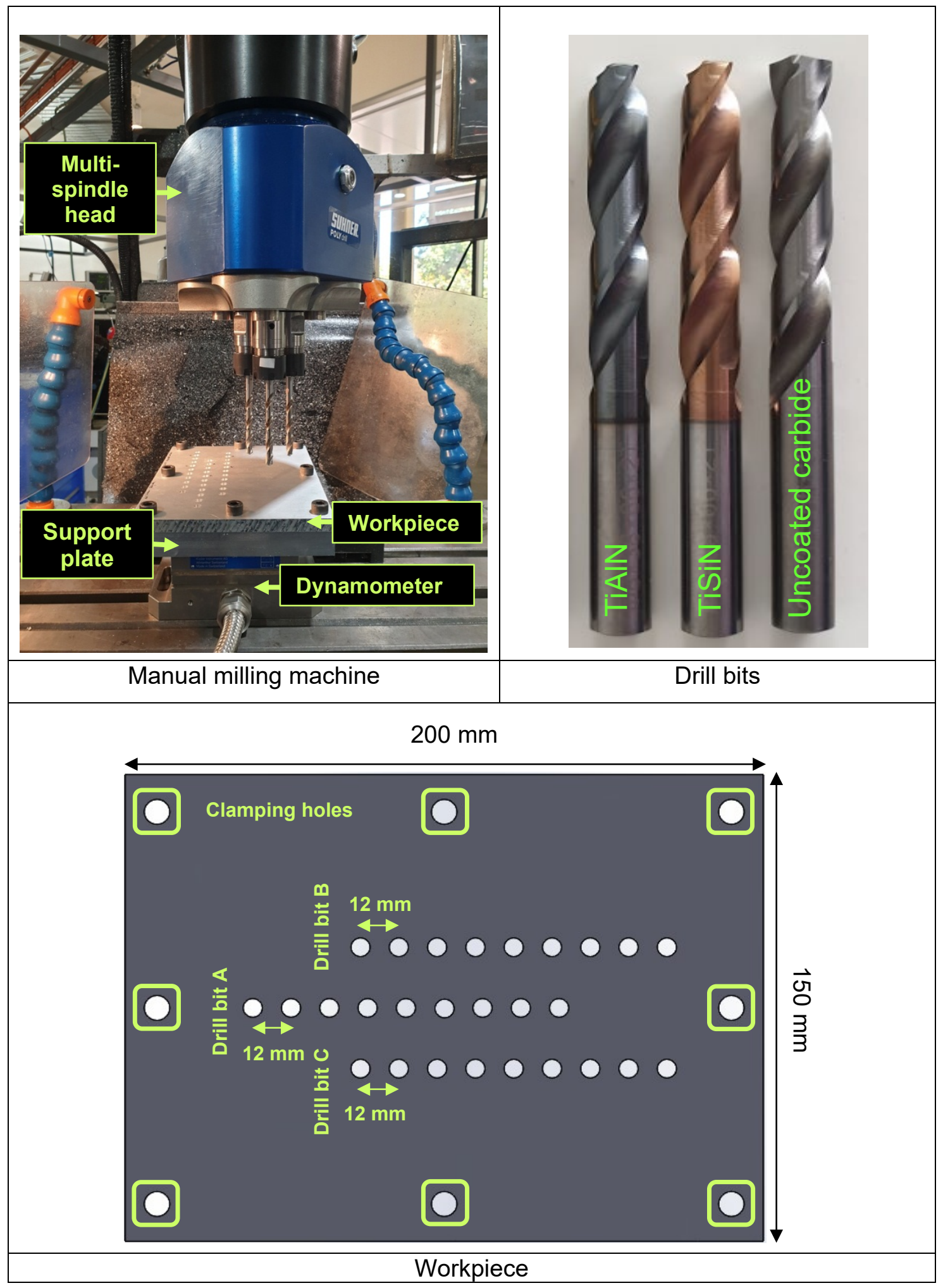

Figure 1: Details of experiments 


\section{Results and discussion}

\subsection{Analysis of thrust force}

Figure 2 shows that the feed had a high influence on average thrust force $\left(F_{z}\right)$ compared to the spindle speed. As the feed was increased, the $F_{z}$ increased, while increasing the spindle speed showed less variation in $F_{z}$. The high generation of $F_{z}$ due to the high feed meant that the tool penetrated faster; therefore, at high feed, the tool has to cut maximum material from the workpiece, which increased the $F_{z}$ due to an increase in uncut chip thickness [28, 29]. Also, at high feed, the load on the tool increased, which increased the $F_{z}$ [30]. It is also shown in Figure 2 that the lowest $F_{z}$ was obtained using the uncoated drills in multi-spindle drilling as compared to the TiAIN- and TiSiN-coated drills. Besides, the value of $F_{z}$ from TiAIN was lower than that obtained from TiSiN-coated drills. This is because of the limited adhesion of the TiSiN coating, despite its increased strength and fatigue properties [31]. However, the difference in $F_{z}$ was insignificant. The rise in $F_{z}$ was less than $7 \%$ for TiAIN, while that of TiSiN was less than $11 \%$ with respect to the $F_{z}$ generated from uncoated carbide drills under the selected drilling parameters.

TiAIN coating contains aluminium which means that it is chemically reactive to aluminium and could easily bond with a cutting surface of the same material, i.e. Al2024. This is mainly due to the metallic crystal and ionic crystal features of TiAIN coating. The chemical reactivity causes the cutting tool and workpiece to adhere together, and some of the cut chip would permanently stick on the cutting tools and cause a built-up edge (BUE). The BUE might be responsible for the slight increase in $F_{z}$ with the increase of spindle speed. However, as shown in Figure 2, the increase in $F_{z}$ is minor, which could be attributed to the low cutting parameters used in the current study. Uncoated carbide drills appear to perform better relative to the coated cutting tools; this could be due to the lower friction of coefficient relative to the other tool coatings. However, this claim is only an assumption since the actual friction coefficient was not measured in the current study and is only based on the data provided by the tool supplier and open literature. Indeed, it can be seen that the performance of uncoated carbide drills becomes similar to TiAIN and TiSiN when drilling at higher spindle speeds. Similarly, it is speculated that drilling at higher spindle speeds beyond $3000 \mathrm{rpm}$ would further increase the $F_{z}$ when drilling using uncoated carbide drills due to the low oxidation temperature of the carbide material $\left(\sim 500{ }^{\circ} \mathrm{C}\right)$. It is also expected that the performance of TiSiN and TiAIN coating in terms of $F_{z}$ would remain similar at higher cutting parameters due to their higher oxidation temperature, which is almost as twice as that for uncoated carbide tools. A firm conclusion can be made -in terms of generated thrust forcesthat drilling Al2024 does not require the use of coated tools when drilling at low spindle 
speeds and feed rates like those used in the current study. Instead, uncoated carbide drills can provide similar or better performance if used for drilling a small number of holes.

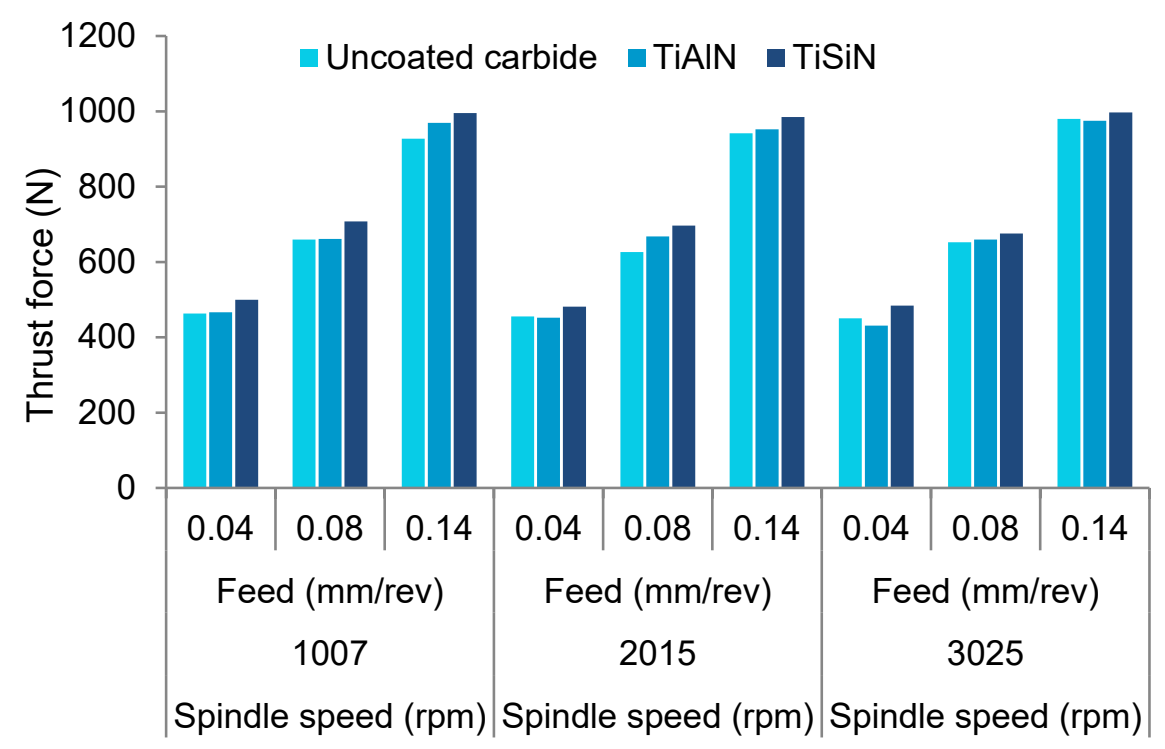

Figure 2 Average thrust force

\subsection{Assessment of hole quality in terms of surface roughness and burrs}

Generally, in industries, surface roughness is usually measured as the average roughness $\left(R_{\mathrm{a}}\right.$ : the arithmetic average of surface heights measured across a surface) [32]. A lower $R_{a}$ indicates a better surface finish, which tends to increase the service life and performance of machined components [8]. Therefore, low $R_{a}$ is always desirable for high-quality holes. Figure 3 shows the $R_{a}$ of uncoated and TiAIN- and TiSiN-coated carbide drills, which shows that both the spindle speed and feed affected the $R_{a}$, irrespective of the coatings on the drill bits. The $R_{a}$ increased as the spindle speed and the feed increase; however, the impact of spindle speed was more than that of feed. The higher $R_{a}$ due to high spindle speed could be due to the high temperature that affects the plastic deformation of the workpiece, which subsequently degraded the surface quality [33]. Also, the high $R_{a}$ due to the high feed might be due to the increased thickness of the chips due to the high thrust force that increased the surface roughness [34]. 


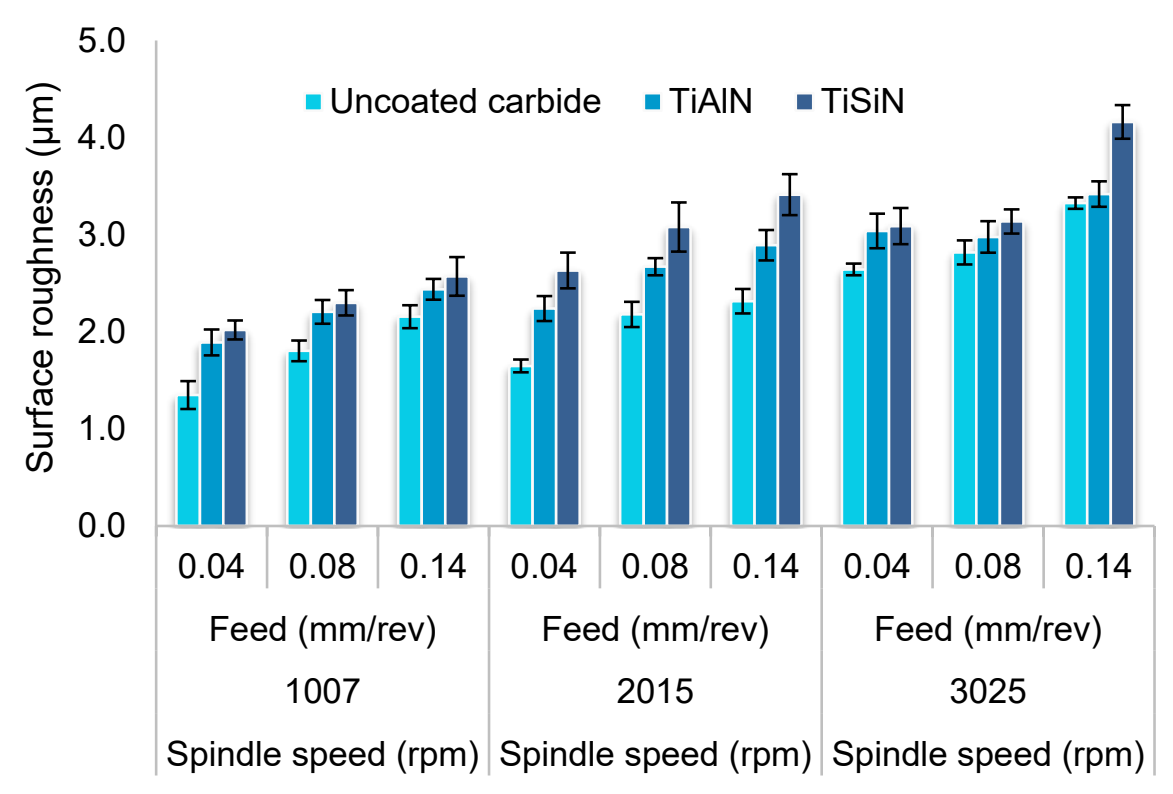

Figure 3 Average surface roughness

Figure 3 also shows that lower $R_{a}$ values were obtained using the uncoated carbide drills following the TiAIN- and TiSiN- coated drills in a multi-spindle simultaneous drilling approach. This could be due to the higher chemical affinity of aluminium for coating materials accumulated on the tools' surface due to the constant release of particles, especially silicon which caused a BUE during dry machining of aluminium. Subsequently, there was a chance of high cutting forces, hence increasing the $R_{a}$ values [35]. Furthermore, it was reported that aluminium-based coatings have some drawbacks for the machining of aluminium because aluminium tends to stick to the workpiece surface. When these coatings come in contact with aluminium, they have abrasive properties that contribute to the progression of BUE [36]. However, the $R_{a}$ in holes drilled using TiAIN coated drills was lower than those drilled using TiSiN coated drills. The reason that TiSiN has a greater $R_{a}$ than TiAIN, despite its high hardness, is that TiSiN coating has restricted adhesion properties than that of TiAIN, which might have led to a reduction in tool life [31]. Besides, the coefficient of friction of TiSiN is greater than that of TiAIN coated tools [21], and according to Prengel et al. [37], the low coefficient of friction reduces the BUE. Hence, smaller $R_{a}$ values can be expected due to the lower cutting loads and less tool wear as a result of coatings' low friction coefficient [15]. Therefore, multi-spindle drilling increases productivity by drilling more than one hole and using uncoated drills would save manufacturing costs. The rise in $R_{a}$ was $28.68 \%$ for TiAIN, while that of TiSiN was $33.22 \%$ with respect to the $R_{a}$ obtained from uncoated carbide drills under the selected drilling parameters.

Apart from the $R_{a}$, another essential characteristic of the hole quality is burrs. According to Min et al. [38], burrs can be a source of dimensional error that interferes with the assembly parts and caused misalignments. Figures 4 show the burrs around the holes examined from 
one of the drill bits of the multi-spindle head at a cutting speed of $3025 \mathrm{rpm}$ and feed of 0.14 $\mathrm{mm} / \mathrm{rev}$. Results showed that more burrs were formed at the entrance of holes than the exit side. Figures 4 also show that neither of the coated drills performs better than the uncoated drills. An insignificant difference was found in burrs produced in multi-spindle drilling using the TiAIN- and TiSiN-coated drill bits.

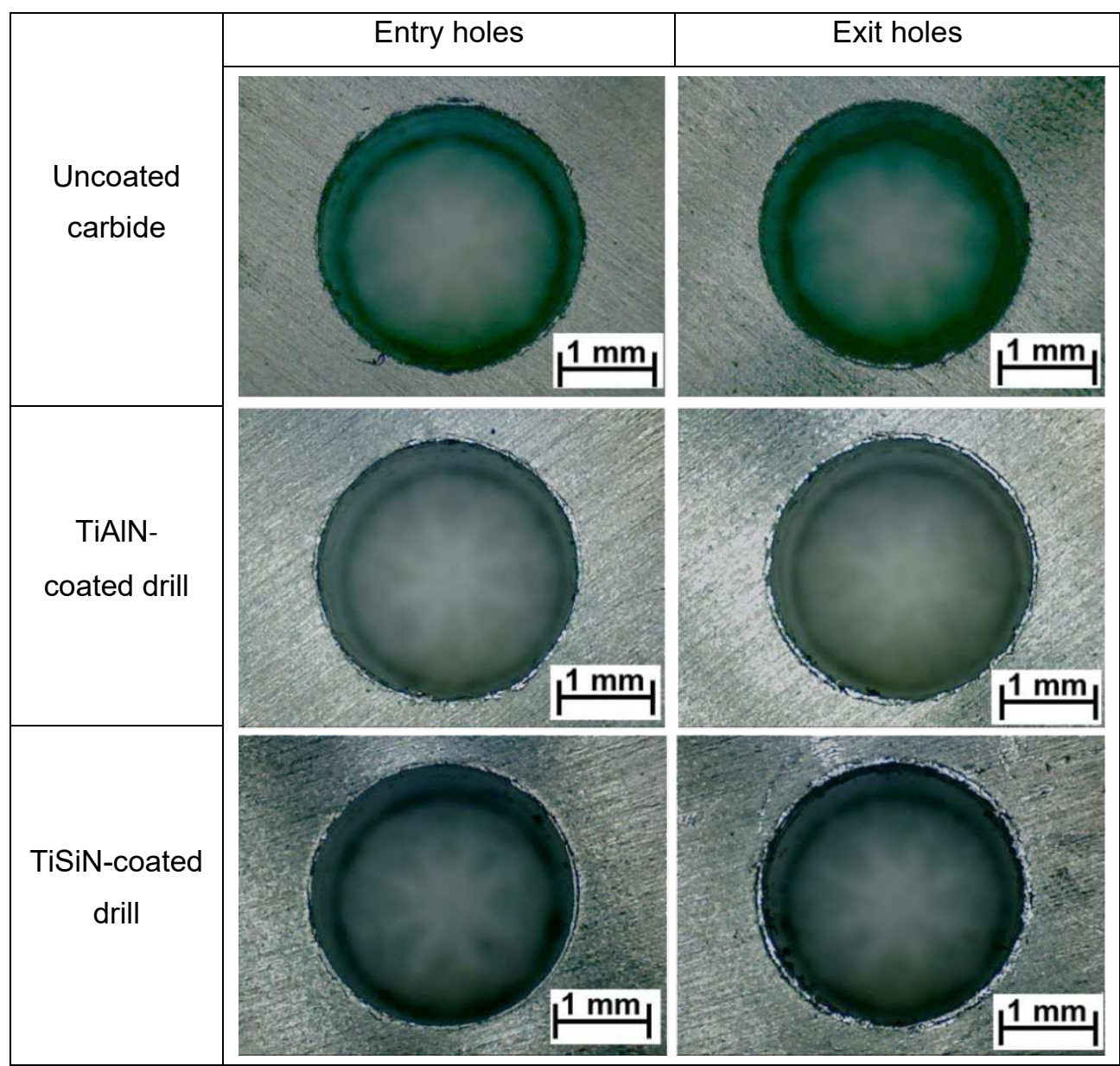

Figure 4 Hole images at cutting speed of $3025 \mathrm{rpm}$ and feed of $0.14 \mathrm{~mm} / \mathrm{rev}$

\subsection{Statistical Analyses}

\subsubsection{Analysis of variance}

Analysis of variance (ANOVA) is a statistical method used to determine the significant parameters on the response and to check how much impact input parameters in any machining process has on the output responses [6]. In this study, ANOVA was performed with a confidence interval of $95 \%(\alpha=0.05)$ based on spindle speed, feed, and coatings of the drills in the multi-spindle drilling approach. The selected responses were thrust force and $R_{a}$. Therefore, the P-value would consider only those values as statistically significant, which are less than 0.05. Additionally, F-values determine whether the significant effect of the parameter has on the quality characteristics. Finally, the percentage contribution describes the influence of each process parameter on the output responses [39]. Table 2 shows the ANOVA results for the thrust force and $R_{a}$. 
Table 2 Analysis of variance

\begin{tabular}{|c|c|c|c|c|c|c|c|}
\hline \multicolumn{8}{|l|}{ Thrust force } \\
\hline Source & DF & Seq SS & Adj SS & Adj MS & F-Value & P-Value & Contribution \\
\hline Model & 18 & 1171529 & 1171529 & 65085 & 447.23 & 0 & $99.90 \%$ \\
\hline Linear & 6 & 1168684 & 1168684 & 194781 & 1338.43 & 0 & $99.66 \%$ \\
\hline$n$ & 2 & 467 & 467 & 234 & 1.61 & 0.259 & $0.04 \%$ \\
\hline$f$ & 2 & 1160014 & 1160014 & 580007 & 3985.51 & 0 & $98.92 \%$ \\
\hline$C$ & 2 & 8203 & 8203 & 4102 & 28.18 & 0 & $0.70 \%$ \\
\hline 2-Way Interactions & 12 & 2845 & 2845 & 237 & 1.63 & 0.249 & $0.24 \%$ \\
\hline$n \times f$ & 4 & 1576 & 1576 & 394 & 2.71 & 0.108 & $0.13 \%$ \\
\hline$n \times C$ & 4 & 718 & 718 & 180 & 1.23 & 0.369 & $0.06 \%$ \\
\hline$f \times C$ & 4 & 551 & 551 & 138 & 0.95 & 0.485 & $0.05 \%$ \\
\hline Error & 8 & 1164 & 1164 & 146 & - & - & $0.10 \%$ \\
\hline Total & 26 & 1172693 & - & - & - & - & $100.00 \%$ \\
\hline \multicolumn{8}{|l|}{ Surface roughness } \\
\hline Model & 18 & 10.2274 & 10.2274 & 0.56819 & 44.05 & 0 & $99.00 \%$ \\
\hline Linear & 6 & 9.6813 & 9.6813 & 1.61356 & 125.08 & 0 & $93.72 \%$ \\
\hline$n$ & 2 & 5.4459 & 5.4459 & 2.72297 & 211.09 & 0 & $52.72 \%$ \\
\hline$f$ & 2 & 2.1104 & 2.1104 & 1.0552 & 81.8 & 0 & $20.43 \%$ \\
\hline$C$ & 2 & 2.125 & 2.125 & 1.06249 & 82.37 & 0 & $20.57 \%$ \\
\hline 2-Way Interactions & 12 & 0.546 & 0.546 & 0.0455 & 3.53 & 0.041 & $5.29 \%$ \\
\hline$n \times f$ & 4 & 0.2034 & 0.2034 & 0.05086 & 3.94 & 0.047 & $1.97 \%$ \\
\hline$n \times C$ & 4 & 0.2531 & 0.2531 & 0.06328 & 4.91 & 0.027 & $2.45 \%$ \\
\hline$f \times C$ & 4 & 0.0895 & 0.0895 & 0.02237 & 1.73 & 0.235 & $0.87 \%$ \\
\hline Error & 8 & 0.1032 & 0.1032 & 0.0129 & - & - & $1.00 \%$ \\
\hline Total & 26 & 10.3305 & - & - & - & - & $100.00 \%$ \\
\hline
\end{tabular}

$n$ : spindle speed, $f$ : feed, $C$ : coatings

The results show that for the thrust force, the most influential parameter was the feed $(98.92 \%)$, followed by a minor contribution from the coating $(0.7 \%)$. The impact of the spindle speed on thrust force and the linear interactions between the studied parameters were found to be insignificant as the $\mathrm{p}$-value is more than 0.05 . For $R_{a}$, spindle speed showed the highest percentage contribution (52.72\%), followed by the coating and the feed with $20.57 \%$ and $20.43 \%$, respectively. Linear interactions between the spindle speed and the other two parameters showed a somewhat minor contribution of less than $2.5 \%$ in increasing the $R_{a}$.

\subsubsection{Regression analysis}

Regression analysis is a statistical method used to develop a regression equation that analyses the correlation between the process parameters and the responses in any machining process [40]. The coefficients in the equations estimate the relationship between each independent variable and the dependent variable. The responses are the dependent or outcome variables, and the predictors are the independent or input variables [41]. Therefore, the essential parts of a regression model include: Dependent Variable $=$ (Constant +Independent Variables) + Error [41]. 
In this study, the equations obtained from the regression analysis are presented as:

Thrust force $=227.7-0.00244$ Spindle speed +5043.7 Feed +20.28 Coatings

$\mathrm{R}^{2}=99.56 \%$

Surface roughness $=0.237+0.000544$ Spindle speed +6.800 Feed +0.3424 Coatings

$\mathrm{R}^{2}=93.30 \%$

$\mathrm{R}^{2}$ is the regression coefficient, which shows the effectiveness of the model [42]. It statistically measures how well the regression line estimates the real data points, where the values between 0.8 and 1 are highly acknowledged [43]. The $\mathrm{R}^{2}$ values in this study are more than 90\%, which indicates that the developed equations are acceptable for the prediction of thrust force and surface roughness in the selected machining variables for the multi-spindle drilling process of Al2024. Furthermore, the adequacy of the model was investigated by analysing residuals, which are the difference between the respective observed responses and the predicted responses [44]. Figure 5 illustrates the normal probability plots for the thrust force and surface roughness which shows that all the residuals almost fall on a straight line, whereas Figure 6 shows the statistical data about the residuals, thus confirming that the regression model matches well with the experimental data and the developed model is highly reliable.
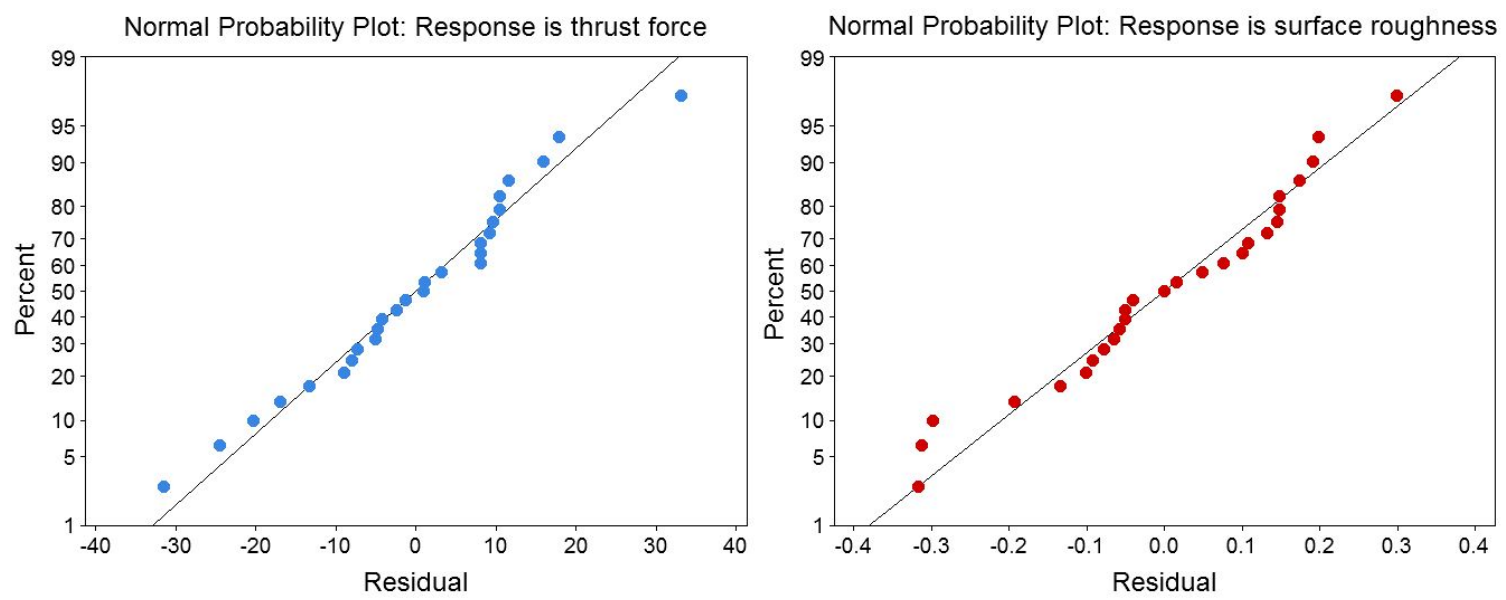

Figure 5 Normal probability plots for thrust force and surface roughness
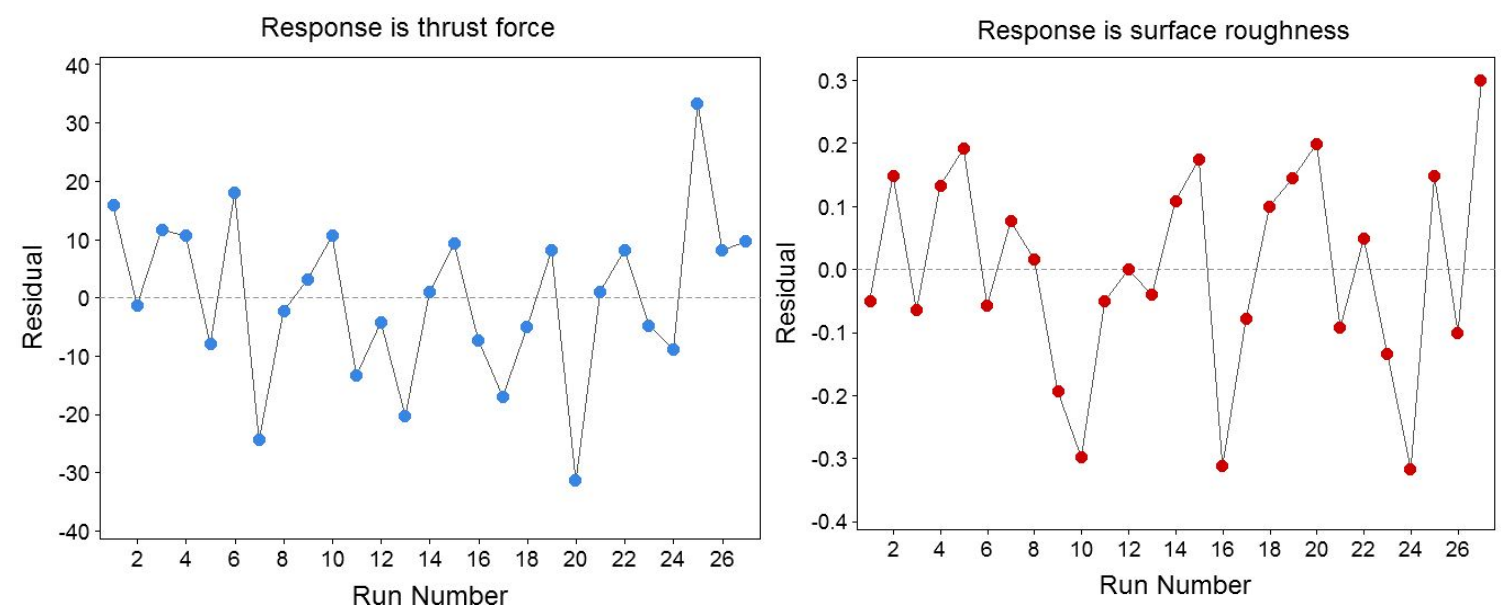
Figure 6 Residual analysis for thrust force and surface roughness

\subsection{Post drilling tool conditions}

The type of tool wear depends on the materials of the tool, the workpiece, and the drilling conditions [35]. Also, as aforementioned, the usual tool wear in dry machining of aluminium is the BUE. Figure 7 shows the condition of one of the uncoated carbide and coated carbide drills used in multi-spindle drill drilling, which reveals the formation of BUE. The high BUE was found on the TiSiN following TiAIN coated drills and the uncoated drills, which also correspond to a reason for surface roughness. According to Bouzakis et al. [31], the good performance of TiAIN than TiSiN was due to the weaker adhesion properties of TiSiN, despite the increased strength. Also, as discussed earlier, the co-efficient of friction of TiSiN is more than TiAIN [21], which increased the tool wear by increasing the tendency of sticking the materials from the workpiece on the tools [15]. Besides, the reason for the high BUE of the coated drills than the uncoated drill bits might be due to the low drilling parameters selected in this study. Therefore, further investigation is required to assess the performance of coated drills at high drilling parameters during the multi-spindle simultaneous drilling process. However, it should be noted that aggressive drilling might either increase the undesirable vibration or cutting temperature that would affect the hole quality [22].
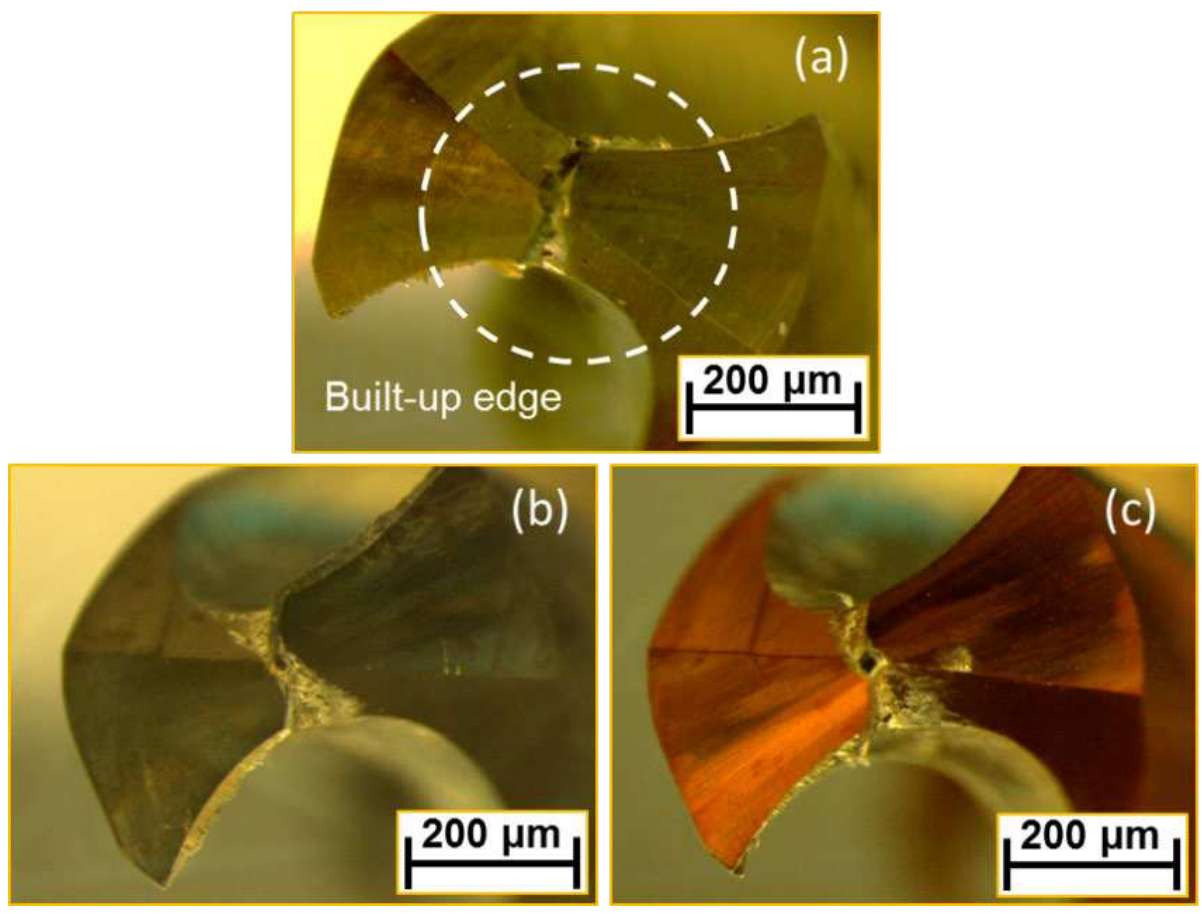

Figure 7 Post-machining tool condition: (a) uncoated carbide (b) TiAIN (c) TiSiN

\section{Conclusions}

This work investigated the use of uncoated carbide and TiAIN- and TiSiN- coated carbide drill bits to ensure high-quality holes in the multi-spindle drilling process for productivity improvement. 
- In general, regardless of the tool coating types, the high feed increased the thrust force, while in the case of surface roughness, both the high spindle speed and feed increased the surface roughness. However, the spindle speed was found more influential than the feed. Furthermore, the burrs at the exit of the holes were more evident than those formed at the entrance of the holes. The burrs were more affected by the feed as compared to the spindle speed.

- The ANOVA results revealed that thrust force was influenced by feed followed by coatings with insignificant impact from the spindle speed. In contrast, the surface roughness was more affected by the spindle speed following the coatings and feed. Also, a regression model was developed with $\mathrm{R}^{2}$ of more than $90 \%$, which means that the developed equations are reliable and can be used to predict thrust force and surface roughness.

- The use of TiAIN- and TiSiN-coated drills compared to the uncoated drills did not significantly lower the thrust force and improve hole quality, such as lowering the surface roughness and less burr formation. The high built-up edge was found on the TiSiN following TiAIN coated drills and the uncoated drills. Therefore, in the multispindle drilling approach, the uncoated carbide drill showed high performance. However, further research is required to assess coated tools at high drilling parameters in the multi-spindle drilling process.

Declaration of Interest: The authors declare that there are no conflicts of interest.

Authors Contributions: Conceptualization: Majid Tolouei-Rad and Muhammad Aamir; methodology: Muhammad Aamir, and Khaled Giasin; investigation and writing original draft: Muhammad Aamir; review and supervision: Majid Tolouei-Rad, and Khaled Giasin.

Funding: This research received no external funding.

Ethical Approval: The article follows the guidelines of the Committee on Publication Ethics (COPE) and involves no studies on human or animal subjects.

Competing Interests: The authors declare that they have no competing interests.

Consent to Participate: Not applicable. The article involves no studies on humans.

Consent to Publish: Not applicable. The article involves no studies on humans.

\section{References}

[1] M. Aamir, M. Tolouei-Rad, K. Giasin, and A. Nosrati, (2019) Recent advances in drilling of carbon fiber-reinforced polymers for aerospace applications: a review. The International Journal of Advanced Manufacturing Technology, 105, 2289-2308.

[2] E. Z. Moghaddam, A. C. Martinez, S. Koochak-Yazdi, and H. Murad, "Industry analysis: The fastener supply chain in aerospace industry," ed: Montreal: McGill University, 2011. 
[3] D. Sun, P. Lemoine, D. Keys, P. Doyle, S. Malinov, Q. Zhao, X. Qin, and Y. Jin, (2018) Holemaking processes and their impacts on the microstructure and fatigue response of aircraft alloys. The International Journal of Advanced Manufacturing Technology, 94, 1719-1726.

[4] D. Sun, D. Keys, Y. Jin, S. Malinov, Q. Zhao, and X. Qin, (2016) Hole-making and its Impact on the Fatigue Response of Ti-6AL-4V Alloy. Procedia CIRP, 56, 289-292.

[5] A. Riley, B. Aardema, P. Vosbury, M. Eiff, H. Frautschy, R. Serkenburg, D. Shaffer, T. Wild, and T. Michmerhuizen, (2008) Aviation maintenance technician handbook. Department of Transportation: Federal Aviation Administration. Newcastle, Wash.

[6] M. Aamir, M. Tolouei-Rad, K. Giasin, and A. Vafadar, (2020) Feasibility of tool configuration and the effect of tool material, and tool geometry in multi-hole simultaneous drilling of Al 2024 . The International Journal of Advanced Manufacturing Technology, 111, 861-879.

[7] S. Sahu, "Performance evaluation of uncoated and multi layer tin coated carbide tool in hard turning," Master of Technology, Department of Mechanical Engineering, National Institute of Technology. Rourkela, India, 2012.

[8] V. Varghese, K. Akhil, M. Ramesh, and D. Chakradhar, (2019) Investigation on the performance of AICrN and AITiN coated cemented carbide inserts during end milling of maraging steel under dry, wet and cryogenic environments. Journal of Manufacturing Processes, 43, 136-144.

[9] S.-S. Cho and K. Komvopoulos, (1997) Wear mechanisms of multi-layer coated cemented carbide cutting tools. Transactions of the ASME, 119, 8-17.

[10] M. Aamir, M. Tolouei-Rad, A. Vafadar, M. N. A. Raja, and K. Giasin, (2020) Performance Analysis of Multi-Spindle Drilling of Al2024 with TiN and TiCN Coated Drills Using Experimental and Artificial Neural Networks Technique. Applied Sciences, 10, 8633.

[11] M. Aamir, K. Giasin, M. Tolouei-Rad, and A. Vafadar, (2020) A review: drilling performance and hole quality of aluminium alloys for aerospace applications. Journal of Materials Research and Technology, 9, 12484-12500.

[12] P. Haja Syeddu Masooth and V. Jayakumar, (2020) Experimental investigation on surface finish of drilled hole by TiAIN, TiN, AICrN coated HSS drill under dry conditions. Materials Today: Proceedings, 22, 315-321.

[13] E. Kuram, (2019) Tool Coating Effect on the Performance in Milling of Al2124 Aluminium Alloy. Dokuz Eylül Üniversitesi Mühendislik Fakültesi Fen ve Mühendislik Dergisi, 21, 749760.

[14] C. Y. Wang, Y. X. Xie, Z. Qin, H. S. Lin, Y. H. Yuan, and Q. M. Wang, (2015) Wear and breakage of TiAIN- and TiSiN-coated carbide tools during high-speed milling of hardened steel. Wear, 336-337, 29-42.

[15] C. Dumkum, P. Jaritngam, and V. Tangwarodomnukun, (2019) Surface characteristics and machining performance of TiAIN-, TiN-and AICrN-coated tungsten carbide drills. Proceedings of the Institution of Mechanical Engineers, Part B: Journal of Engineering Manufacture, 233, 1075-1086.

[16] M. Kurt, Y. Kaynak, and E. Bagci, (2008) Evaluation of drilled hole quality in Al 2024 alloy. The International Journal of Advanced Manufacturing Technology, 37, 1051-1060.

[17] M. Tolouei-Rad and S. Zolfaghari, (2009) Productivity improvement using Special-Purpose Modular machine tools. International Journal of Manufacturing Research, 4, 219-235.

[18] M. Tolouei-Rad, (2003) An efficient algorithm for automatic machining sequence planning in milling operations. International Journal of Production Research, 41, 4115-4131.

[19] M. Tolouei-Rad, (2011) An intelligent approach to high quantity automated machining. Journal of Achievements in Materials and Manufacturing Engineering, 47, 195-204.

[20] M. Tolouei-Rad, "Intelligent analysis of utilization of special purpose machines for drilling operations," in Intelligent Systems, Prof. Vladimir M. Koleshko (Ed.), ISBN: 978-953-51-00546, InTech, Available from: http://www.intechopen.com/books/intelligent-systems/intelligentanalysis-of-utilization-of-special-purposemachines-for-drilling-operations. Croatia, 2012, ch. 14, pp. 297-320.

[21] Statoncoating. "Coatings for cutting tools." https://www.statoncoating.com/en/coatings/coatings-cutting-tools (accessed 18 August, 2020). 
[22] R. Hamade and F. Ismail, (2005) A case for aggressive drilling of aluminum. Journal of materials processing technology, 166, 86-97.

[23] K. Giasin, A. Hodzic, V. Phadnis, and S. Ayvar-Soberanis, (2016) Assessment of cutting forces and hole quality in drilling Al2024 aluminium alloy: experimental and finite element study. The International Journal of Advanced Manufacturing Technology, 87, 2041-2061.

[24] N. C. Engdahl. CVD diamond coated rotating tools for composite machining, 2006.

[25] J. Y. Sheikh-Ahmad, Machining of polymer composites. USA: Springer, Boston, MA, 2009.

[26] M. Aamir, M. Tolouei-Rad, K. Giasin, and A. Vafadar, (2020) Machinability of Al2024, Al6061, and Al5083 alloys using multi-hole simultaneous drilling approach. Journal of Materials Research and Technology, 9, 10991-11002.

[27] M. Aamir, S. Tu, K. Giasin, and M. Tolouei-Rad, (2020) Multi-hole simultaneous drilling of aluminium alloy: A preliminary study and evaluation against one-shot drilling process. Journal of Materials Research and Technology, 9, 3994-4006.

[28] M. I. Hanif, M. Aamir, N. Ahmed, S. Maqsood, R. Muhammad, R. Akhtar, and I. Hussain, (2019) Optimization of facing process by indigenously developed force dynamometer. The International Journal of Advanced Manufacturing Technology, 100, 1893-1905.

[29] M. I. Hanif, M. Aamir, R. Muhammad, N. Ahmed, and S. Maqsood, (2015) Design and development of low cost compact force dynamometer for cutting forces measurements and process parameters optimization in turning applications. Int J Innov Sci, 3, 306-3016.

[30] K. Palanikumar and A. Muniaraj, (2014) Experimental investigation and analysis of thrust force in drilling cast hybrid metal matrix (Al-15\% SiC-4\% graphite) composites. Measurement, 53, 240-250.

[31] K.-D. Bouzakis, G. Skordaris, S. Gerardis, G. Katirtzoglou, S. Makrimallakis, M. Pappa, E. Lill, and R. M'Saoubi, (2009) Ambient and elevated temperature properties of TiN, TiAIN and TiSiN PVD films and their impact on the cutting performance of coated carbide tools. Surface and Coatings Technology, 204, 1061-1065.

[32] M. Ratnam, (2017) Factors affecting surface roughness in finish turning. In: Comprehensive materials finishing. Elsevier, 1, 1-25.

[33] K. Giasin, S. Ayvar-Soberanis, T. French, and V. Phadnis, (2017) 3D finite element modelling of cutting forces in drilling fibre metal laminates and experimental hole quality analysis. Applied Composite Materials, 24, 113-137.

[34] Z. Zhu, K. Guo, J. Sun, J. Li, Y. Liu, Y. Zheng, and L. Chen, (2018) Evaluation of novel tool geometries in dry drilling aluminium 2024-T351/titanium Ti6Al4V stack. Journal of Materials Processing Technology, 259, 270-281.

[35] P. Roy, S. Sarangi, A. Ghosh, and A. Chattopadhyay, (2009) Machinability study of pure aluminium and $\mathrm{Al}-12 \% \mathrm{Si}$ alloys against uncoated and coated carbide inserts. International Journal of Refractory Metals and Hard Materials, 27, 535-544.

[36] E. J. Thorne. "Cutting Tool Engineering-Aluminum can be hard to drill, despite its easy rep." https://www.ctemag.com/news/articles/aluminum-can-be-hard-drill-despite-its-easy-rep\# (accessed 17 August, 2020).

[37] H. Prengel, W. Pfouts, and A. Santhanam, (1998) State of the art in hard coatings for carbide cutting tools. Surface and Coatings Technology, 102, 183-190.

[38] S. Min, J. Kim, and D. A. Dornfeld, (2001) Development of a drilling burr control chart for low alloy steel, AISI 4118. Journal of materials processing technology, 113, 4-9.

[39] S. Neseli, (2014) Optimization of process parameters with minimum thrust force and torque in drilling operation using Taguchi method. Advances in Mechanical Engineering, 6, 925382.

[40] M. C. Douglas, Design and Analysis of Experiments, Seventh ed. Wiley: New Delhi, India, , 2011.

[41] J. Frost. "When Should I Use Regression Analysis?" https://statisticsbyjim.com/regression/when-use-regressionanalysis/\#: :text=Use\%20regression\%20analysis\%20to\%20describe,variable\%20and\%20the \%20dependent\%20variable. (accessed 15 September, 2020).

[42] M. Kurt, E. Bagci, and Y. Kaynak, (2009) Application of Taguchi methods in the optimization of cutting parameters for surface finish and hole diameter accuracy in dry drilling processes. The International Journal of Advanced Manufacturing Technology, 40, 458-469. 
[43] J. Prasanna, L. Karunamoorthy, M. V. Raman, S. Prashanth, and D. R. Chordia, (2014) Optimization of process parameters of small hole dry drilling in Ti-6Al-4V using Taguchi and grey relational analysis. Measurement, 48, 346-354.

[44] M. J. Davidson, K. Balasubramanian, and G. Tagore, (2008) Surface roughness prediction of flow-formed AA6061 alloy by design of experiments. Journal of materials processing technology, 202, 41-46. 
Figures

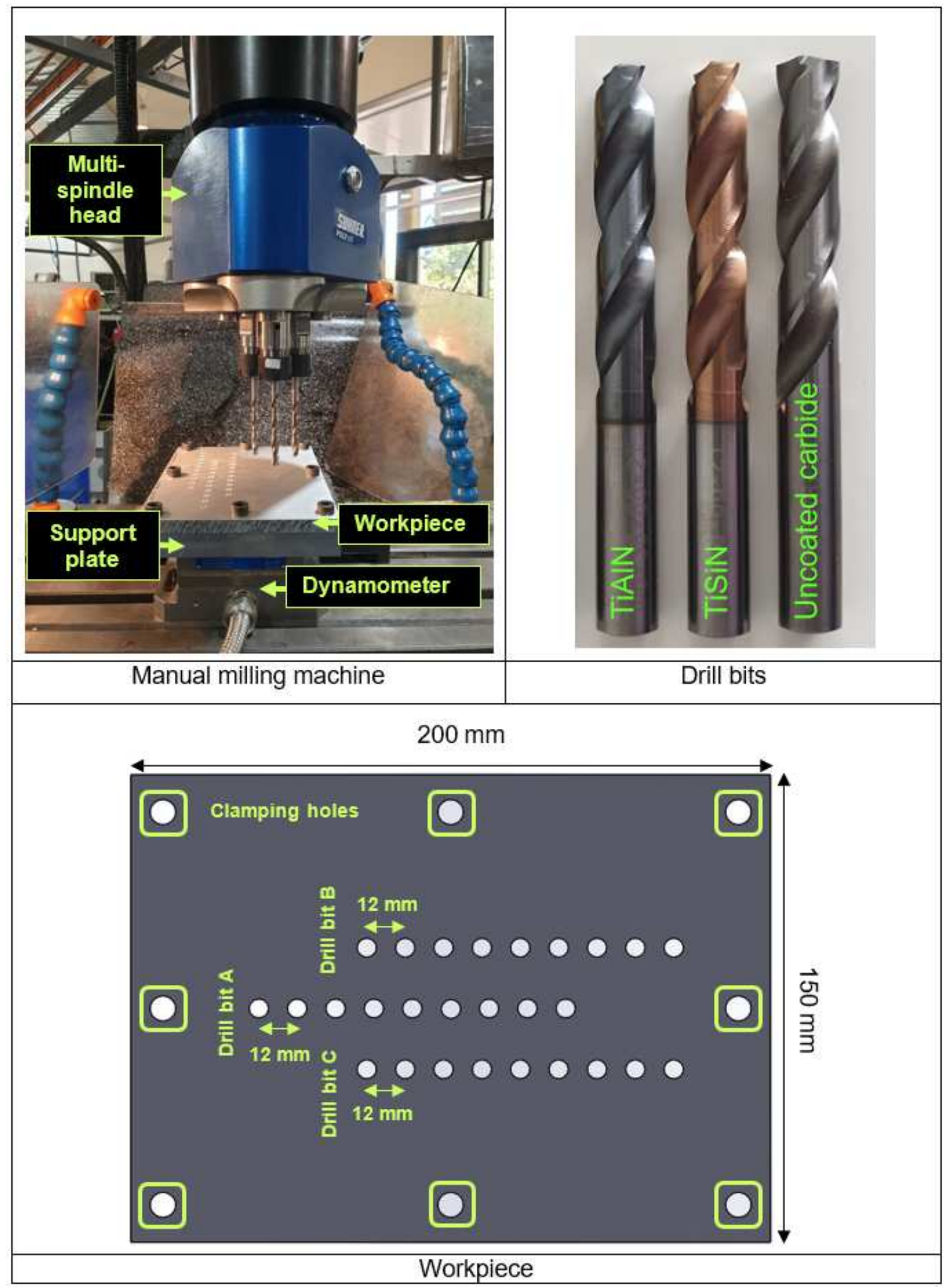

Figure 1

Details of experiments 


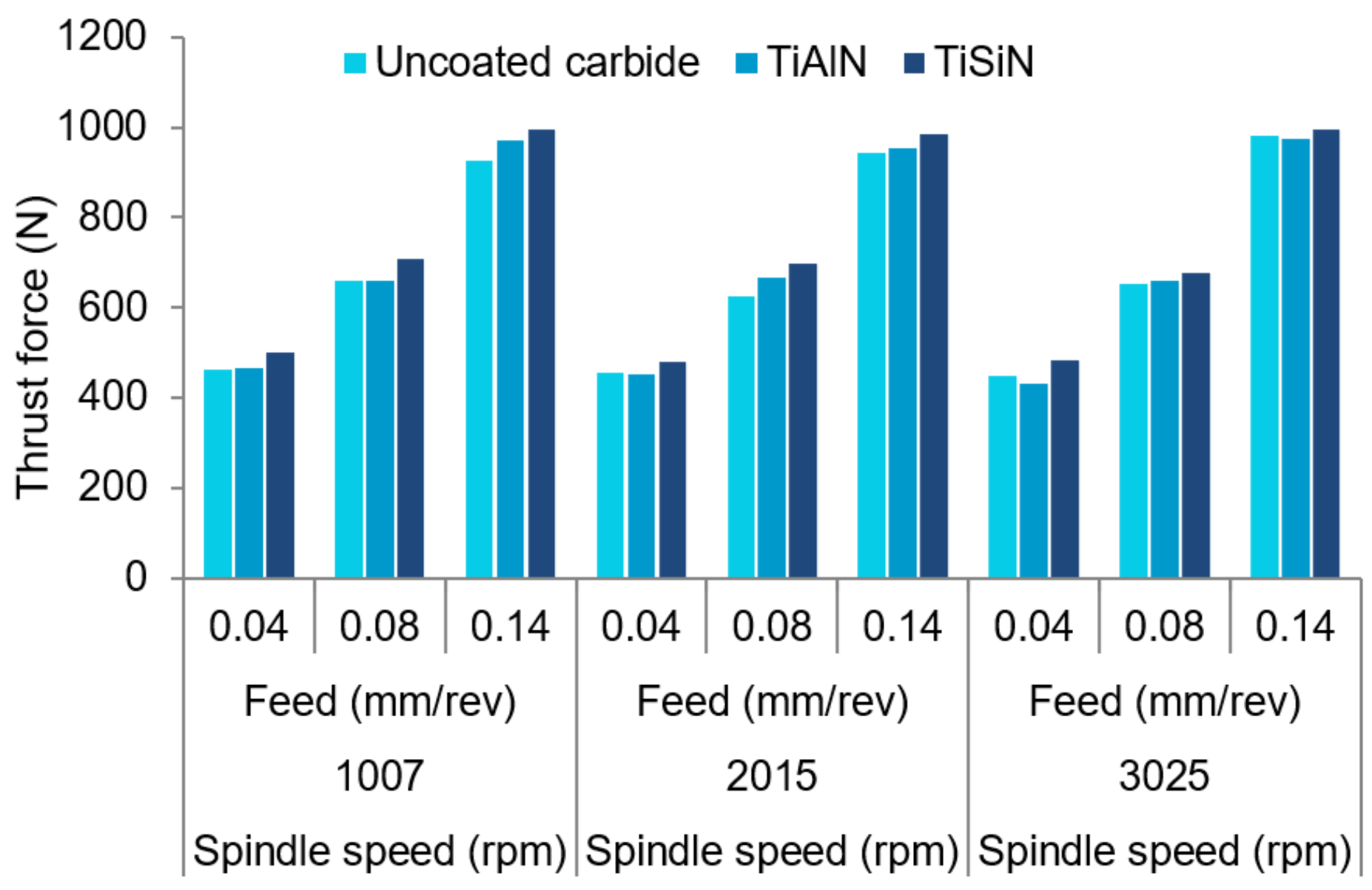

Figure 2

Average thrust force 


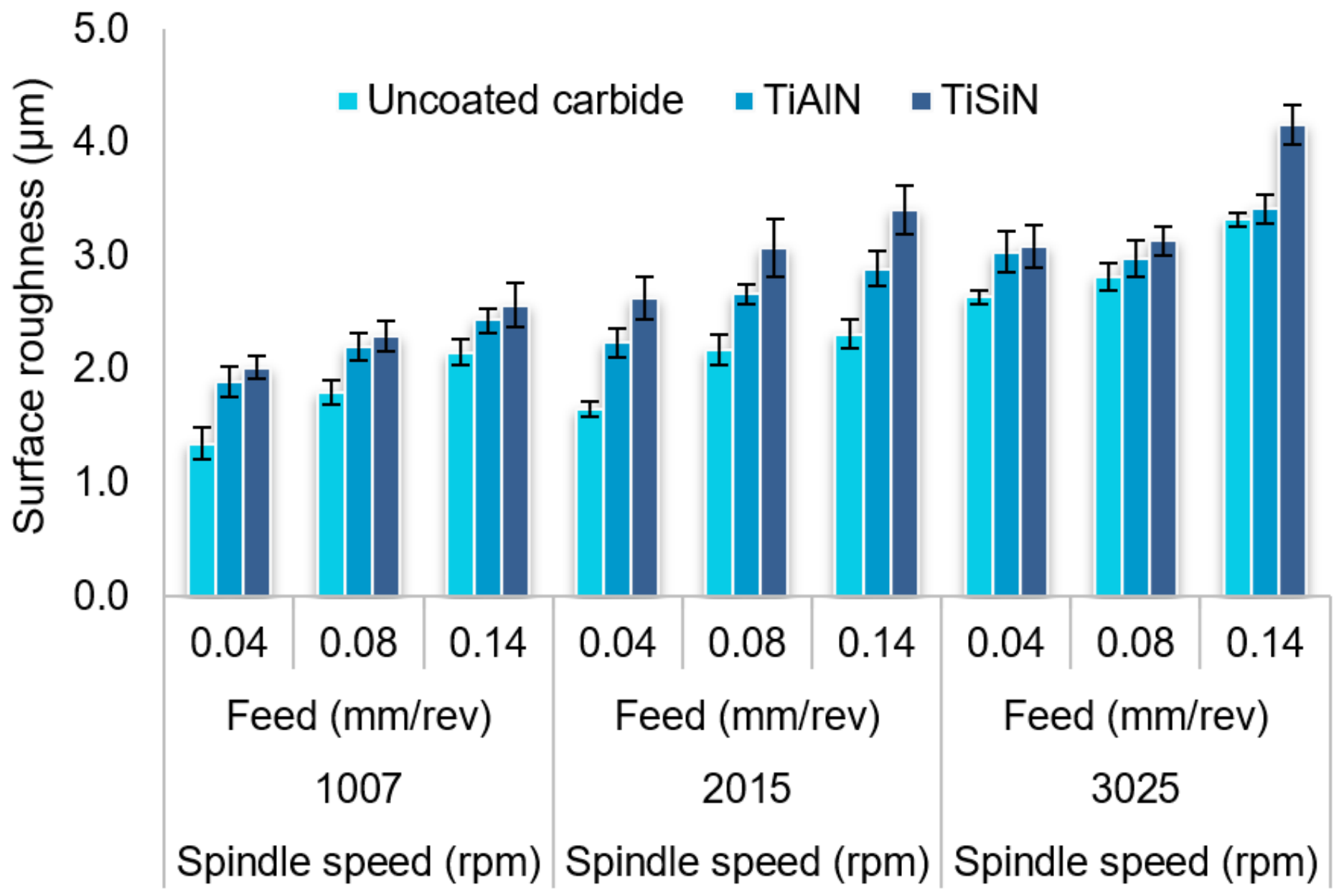

Figure 3

Average surface roughness 


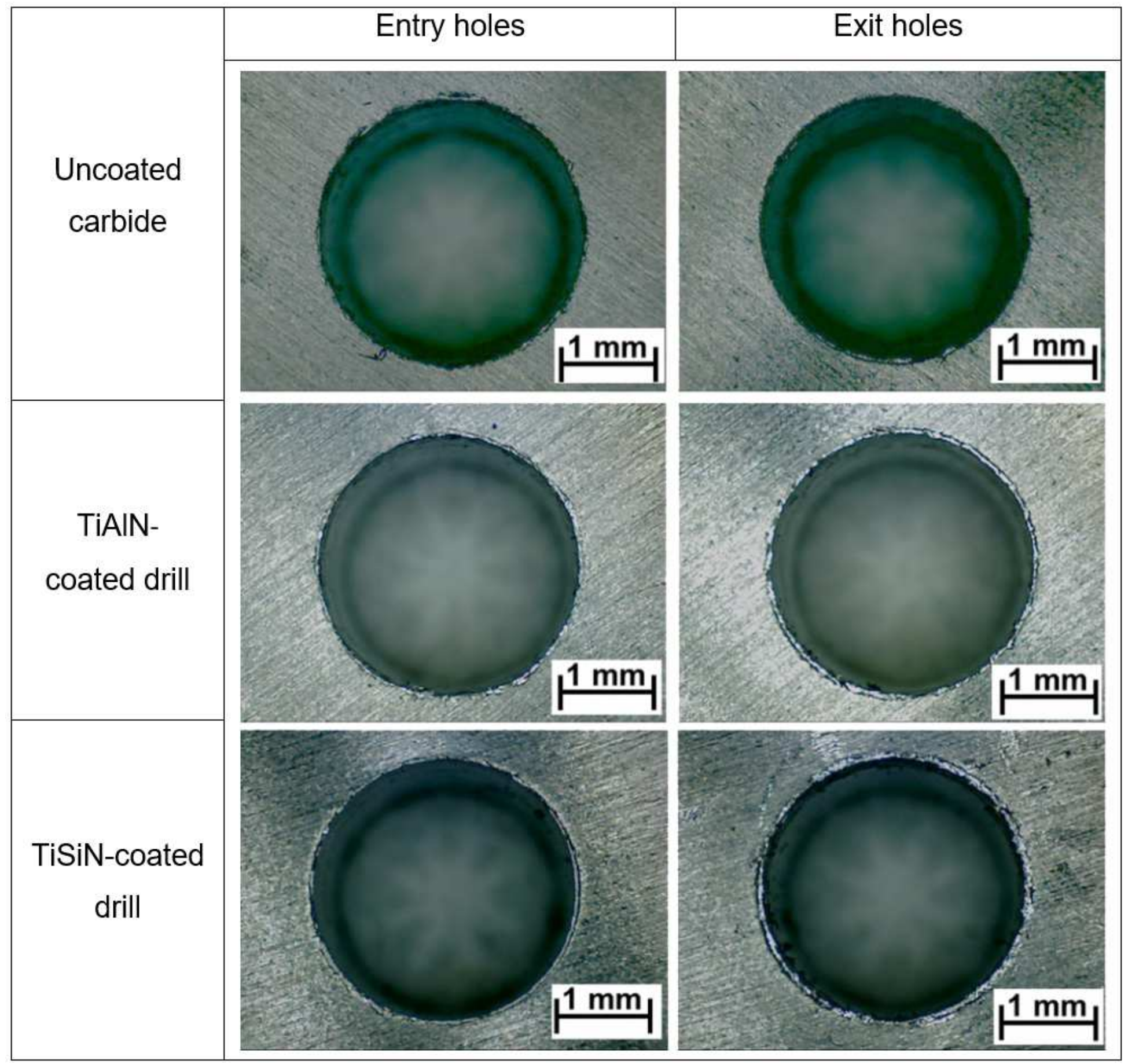

Figure 4

Hole images at cutting speed of $3025 \mathrm{rpm}$ and feed of $0.14 \mathrm{~mm} / \mathrm{rev}$ 

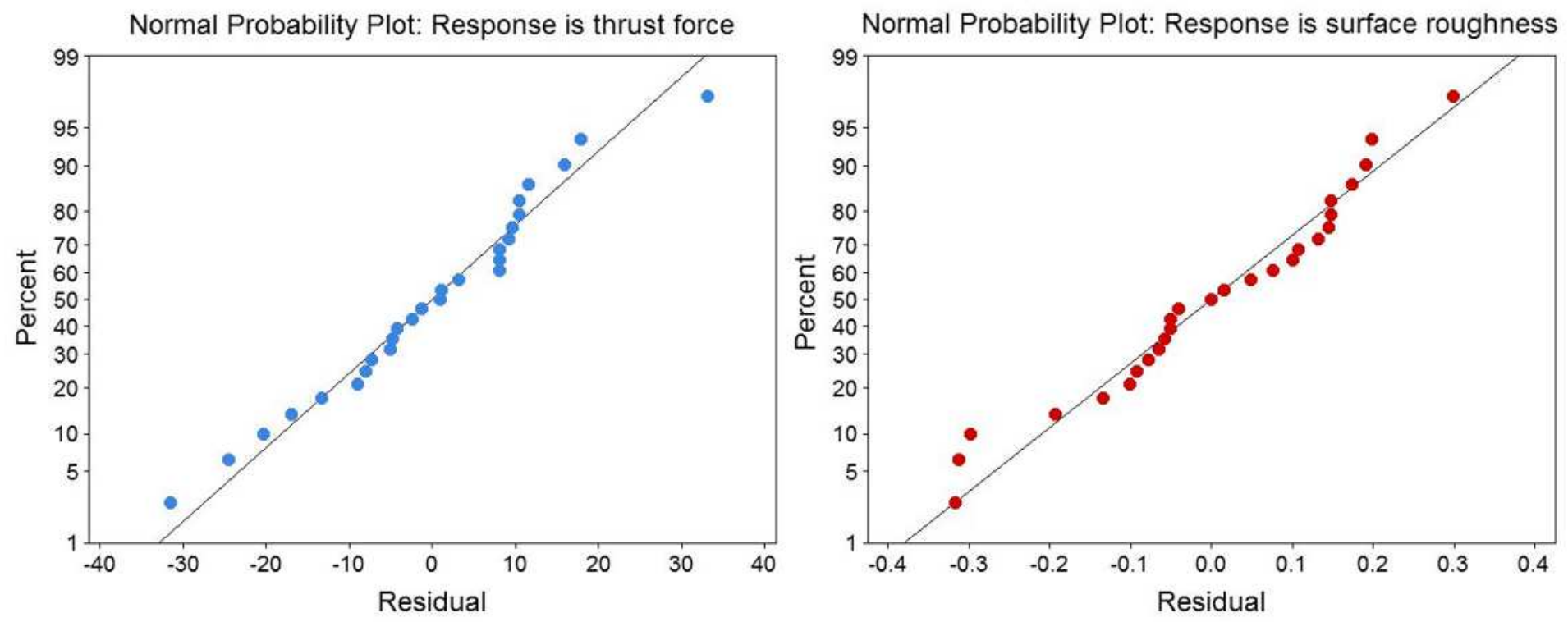

Figure 5

Normal probability plots for thrust force and surface roughness
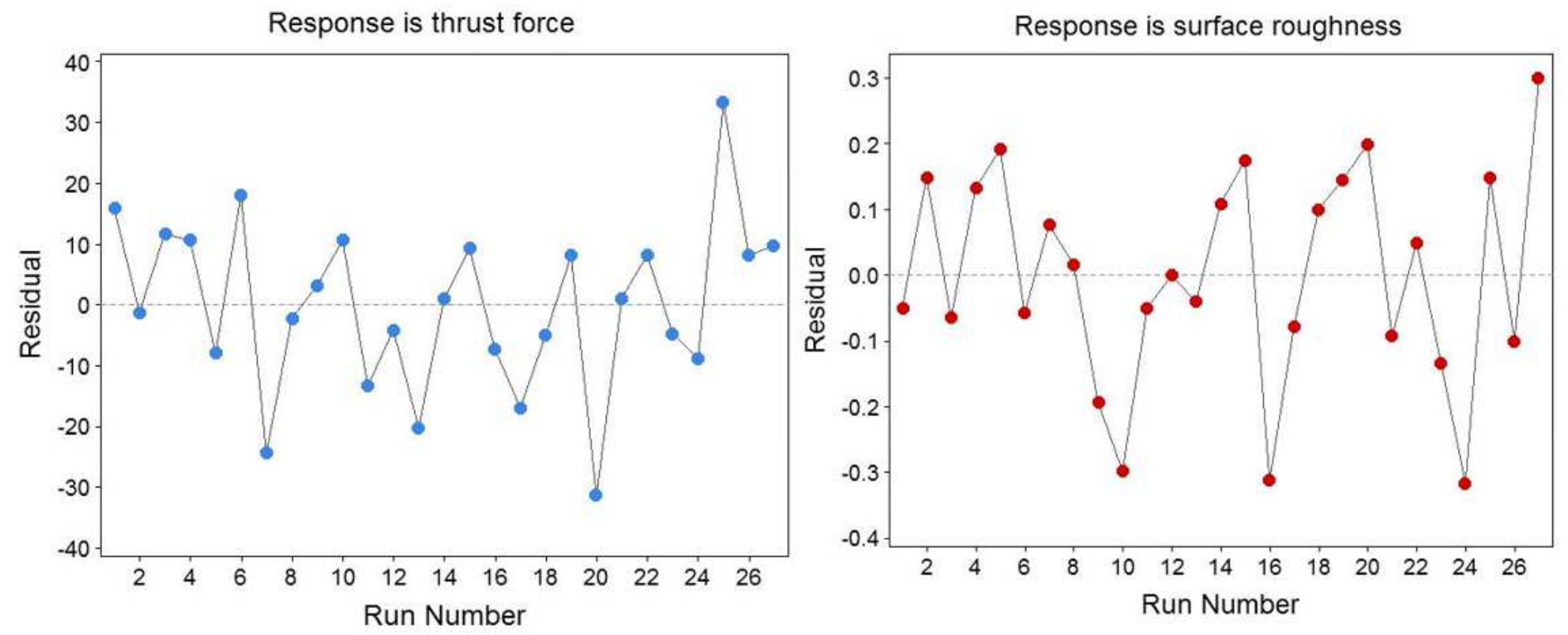

\section{Figure 6}

Residual analysis for thrust force and surface roughness 

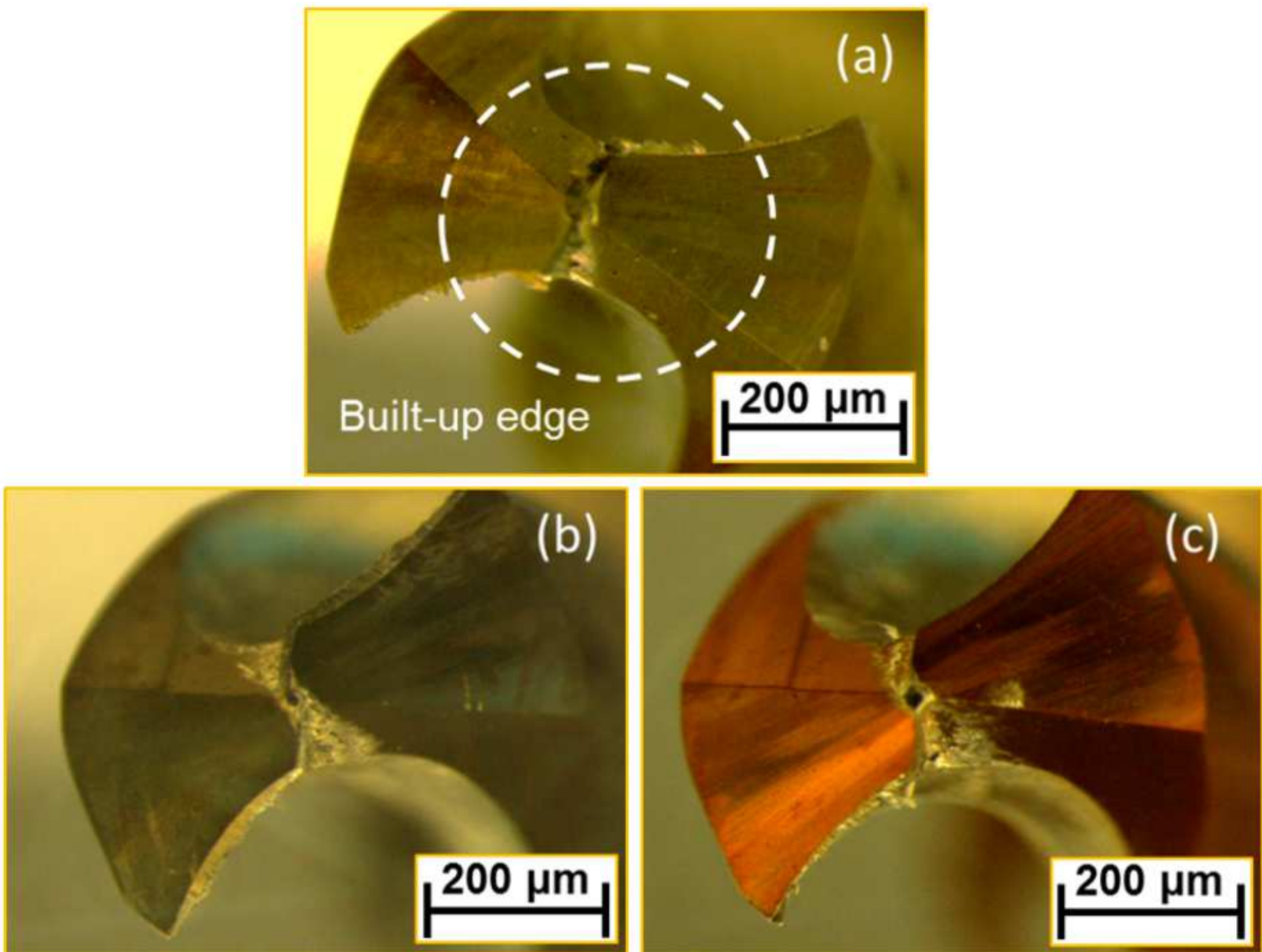

Figure 7

Post-machining tool condition: (a) uncoated carbide (b) TiAIN (c) TiSiN 